\title{
Estudio Histomorfológico Comparativo del Endometrio de Ovejas Prepúberes de Razas de Distinta Prolificidad
}

\author{
Comparative Histomorphological Study of Prepuberal Ewe Endometrio of Different Prolificity Races
}

\author{
Adriana Vasconcellos C.; Johannna Carrasco R. \& Fernando Valdés F.
}

\begin{abstract}
VASCONCELLOS, C. A.; CARRASCO, R. J. \& VALDÉS, F. F. Estudio histomorfológico comparativo del endometrio de ovejas prepúberes de razas de distinta prolificidad. Int. J. Morphol., 26(1):143-148, 2008.

RESUMEN: El objetivo del presente estudio fue sentar bases morfológicas para realizar análisis inmunocitoquímicos e hibridación in situ de la presencia y distribución de receptores de estrógeno y progesterona en ovejas de distinta prolificidad y en distintos planos de nutrición, centrando nuestro interés en el endometrio por su relevancia en los mecanismos reproductivos. Se utilizaron ovejas prepúberes Romney Mash de alta prolificidad $(n=2)$ y Araucanas de prolificidad standard( $n=2)$ de las cuales inmediatamente después del sacrificio se tomaron muestras para estudio histológico del útero, oviducto y ovario. Para el análisis histológico los cortes fueron teñidos con Hematoxilina-Eosina, Van Giesson, Arteta y Ácido Periódico de Schiff (P.A.S.). Los resultados mostraron en las dos razas adecuado desarrollo endometrial, con áreas carunculares e intercarunculares glandulares bien desarrolladas indispensables estas últimas para una buena implantación y crecimiento del embrión. Las glándulas, numerosas, eran tubulares, tortuosas, algo ramificadas y se extendían hasta el miometrio. No se observaron diferencias histológicas significativas entre ambas razas ni cambios morfológicos durante el transcurso de los días 93 al día 117 post natal, siendo su aspecto similar al de endometrio de la oveja adulta.
\end{abstract}

PALABRAS CLAVE: Ovejas; Histoendometrio; Prepúber; Prolificidad.

\section{INTRODUCCIÓN}

La reproducción es un fenómeno fisiológico complejo en el que cada especie animal y sus diferentes razas presentan particularidades que es conveniente conocer.

La importancia de las hormonas a nivel del aparato reproductor de la hembra ovina ha sido tema de numerosos trabajos. Se ha descrito su acción sobre el desarrollo del útero y sobre los cambios histomorfologicos que ellas inducen durante el periodo fetal, neonatal (Wiley et al., 1987) y durante sus fases reproductivas (Priedkkalns, 1993; Jainudeen, 2002). Los factores endocrinos actuarían en forma dinámica en la morfogénesis y citodiferenciación del endometrio produciendo finalmente una reestructuración endometrial con formación de estructuras mucosas nodulares superficiales (carúnculas aglandulares ) y zonas profundas internodulares (carúnculas glandulares) (Carpenter et al., 2003a; Priedkkalns).

Durante el periodo perinatal y neonatal se observa estimulación del desarrollo y diferenciación glandular, las glándulas ausentes en el útero fetal, comienzan a esbozarse como pliegues superficiales del epitelio luminal intercaruncular, el epitelio prolifera en el estroma y forma túbulos que comienzan a enrollarse y ramificarse las puntas (día 7 a día 21) fenómeno que se acentúa en el transcurso de los días, hacia el día 56 la morfogénesis uterina esta esencialmente completa.

Varios son los factores que intervienen en la morfogénesis uterina (factores hormonales, celulares y mecanismos moleculares aún no definidos), sin embargo, es indispensable la activación de los receptores de estrógeno alfa para que se produzca la proliferación glandular endometrial en la oveja neonata (Carpenter et al., 2003a y 2003b). Las glándulas endometriales ya desarrolladas van a sintetizar, secretar y transportar sustancias que son necesarias para la posterior implantación y crecimiento embriofetal (Gray et al., 2002)

Durante la prepubertad los cambios en el endometrio no son muy llamativos ya que en el animal inmaduro los niveles circulantes de estradiol son bajos dado que el ovario 
no lo produce en cantidades apreciables, se mantiene así entre el nacimiento y el día 56 postnatal (Carpenter et al., 2003b y Carpenter et al., 2004). La pubertad comienza con la primera ovulación que va a constituir el primer ciclo estral el cual es regulado por una secuencia rítmica intrínseca del eje hipotálamo- hipófisis-ovarios, que es a su vez modulada por factores ambientales y factores neuroendocrinos internos (Cunningham, 1998; Jainudeen; Kimmins \& Mac Laren, 2001). La correlación cronológica de los fenómenos que tienen lugar en el endometrio con los del ovario se establece gracias a las hormonas ováricas. Los estrógenos secretados ahora en gran cantidad por los folículos estimulan el crecimiento del endometrio y también actúan sobre el sistema nervioso central para provocar la receptividad sexual y correspondientes manifestaciones de celo.

El objetivo del presente trabajo fue realizar un estudio del endometrio de ovejas prepúberes como base morfológica para la realización posterior de análisis inmunocitoquímicos e hibridación in situ, lo que sería de gran valor para la interpretación de los mecanismos de control endocrino en razas diferentes de esta especie y con planos de nutrición distintos.

\section{MATERIAL Y MÉTODO}

Se utilizaron 4 ovejas prepúberes que fueron mantenidas el Campo Eperimental Maquehue de la Universidad de La Frontera (Lat $38^{\circ}$ Lat Sur, 72 m.s.n.m.) ubicado en la IX Región Chile. Dos de las ovejas correspondían a hembras de 93 días de edad, cuyas madres provenían de una cruza de alta prolificidad formada a partir de ovejas Romney Marsh con carneros Finnish Landrace que registran partos dobles y triples llegando a una prolificidad de 150 a $200 \%$. Las otras 2 ovejas correspondían a hembras prepúberes de 113 y 117 días de edad pertenecientes al genotipo local denominado raza Araucana que se caracteriza por su gran adaptación al medio y que presenta en el sur de Chile un 9,6$20 \%$ de partos dobles alcanzando una prolifícidad de 109120\% (Neculman, 1991; Sepúlveda et al., 2007).

Inmediatamente después del sacrificio de los animales se tomaron de cada útero muestras de los dos cuernos en corte transversal y del cuerpo del útero restante un corte longitudinal. Las muestras fueron fijadas en Bouin acuoso, para su estudio histológico. Las inclusiones se hicieron en paraplast (Histhosec, Lab. Merck, Alemania), de las cuales se obtuvieron cortes seriados de 5-7 micras. Los análisis morfológicos fueron teñidos con Hematoxilina y Eosina, Arteta, Van Giesson y Ácido Periódico de Schiff (PAS), (Lab. Merck, Alemania).
Como control se utilizaron muestras de útero de ovejas Romney Marsh adultas uníparas y multíparas

El estudio morfológico y las fotografías se realizaron con un microscopio Carl Zeiss, Axiolab con equipamiento fotógrafico MC $80 \mathrm{DX}$.

\section{RESULTADOS}

Las ovejas prepúberes de ambas razas Romney Mash (Fig.1) Araucanas (Figs. 2 y 3) mostraron endometrio con zona funcional bien desarrollada recubierta por epitelio cilíndrico simple, en áreas seudoestratificado, con mucina. En la región subepitelial se diferencian claramente dos tipos de áreas: áreas carúnculares aglandulares de estroma denso rico en fibroblastos muy vascularizado y áreas intercarunculares glandulares constituidas por tejido conjuntivo laxo, menos celular en la porción basal, con glándulas tubulares ramificadas arrolladas recubiertas por epitelio cilíndrico simple tanto ciliado como no ciliado y estroma bien vascularizado con muchos fibroblastos, mácrofagos, mastocitos y algunos melanocitos. Estos últimos eran muy numerosos en la oveja araucana de 113 días (Fig. 3). Tampoco varió la imagen histológica durante el periodo postnatal entre los días 93 hasta el día 117: ovejas RM: 93 días postnatal (DPN) (Fig. 1) y las Araucanas DPN: 113 (Fig. 2) y DPN:117(Fig. 3). Usamos como control 2 ovejas adultas Romney Mash, una unípara y otra gran multípara, siendo el aspecto histológico y el desarrollo glandular de las ovejas prepúberes similar al de la oveja adulta unípara (Fig. 4); en la oveja multípara es llamativa la presencia de vasos sanguíneos más numerosos y más prominentes tanto en la región caruncular como en la región intercaruncular (Fig. 5).

No se observaron diferencias histológicas significativas entre ambas razas ni cambios morfológicos durante el transcurso de los días 93 al día 117 post natal, siendo su aspecto similar al de endometrio de la oveja adulta unípara.

\section{DISCUSIÓN}

El útero de la oveja desde el punto de vista anatómico es de tipo bicorneado caracterizado por un cuerpo uterino pequeño, anterior al canal cervical y dos cuernos largos bien definidos. Histológicamente presenta 3 túnicas que, de fuera adentro son: a) la serosa (tejido conjuntivo y mesotelio) o adventicia; b) miometrio, túnica de músculo liso y el c) endometrio, que es una mucosa. La mucosa 


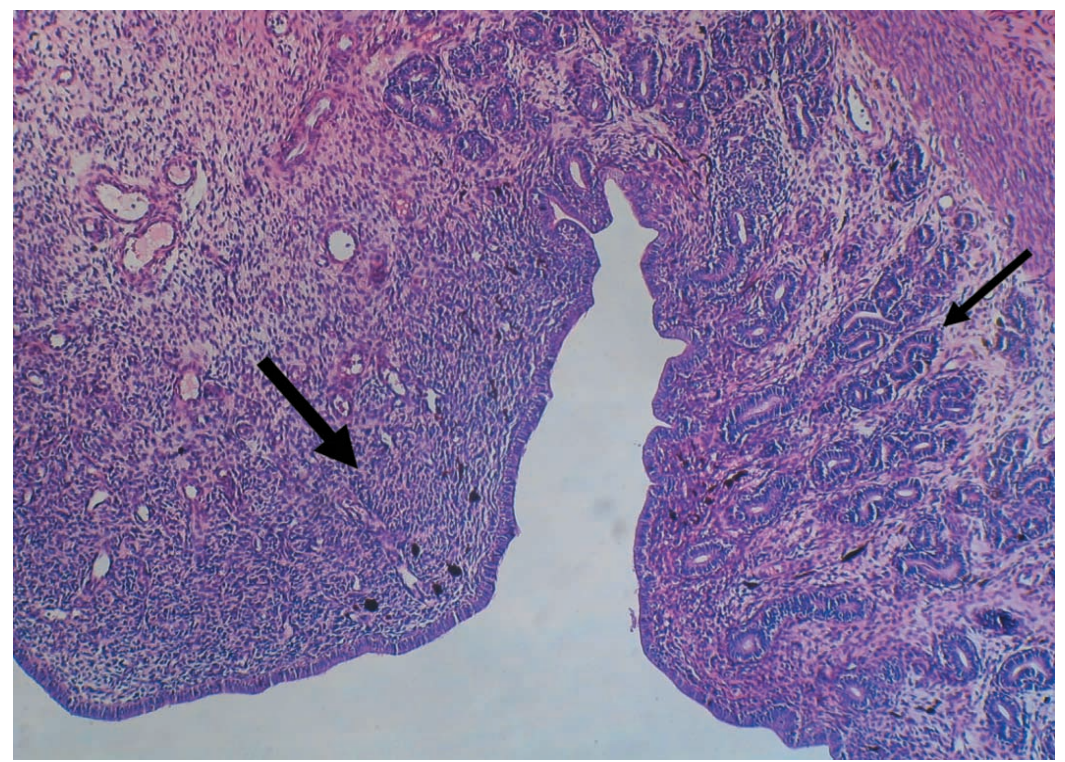

Fig. 1. Endometrio de oveja prepúber Romney Marsh, con zonas intercarunculares glandulares (flecha delgada) y áreas carunculares aglandulares (flecha gruesa). HE. $40 \mathrm{X}$.

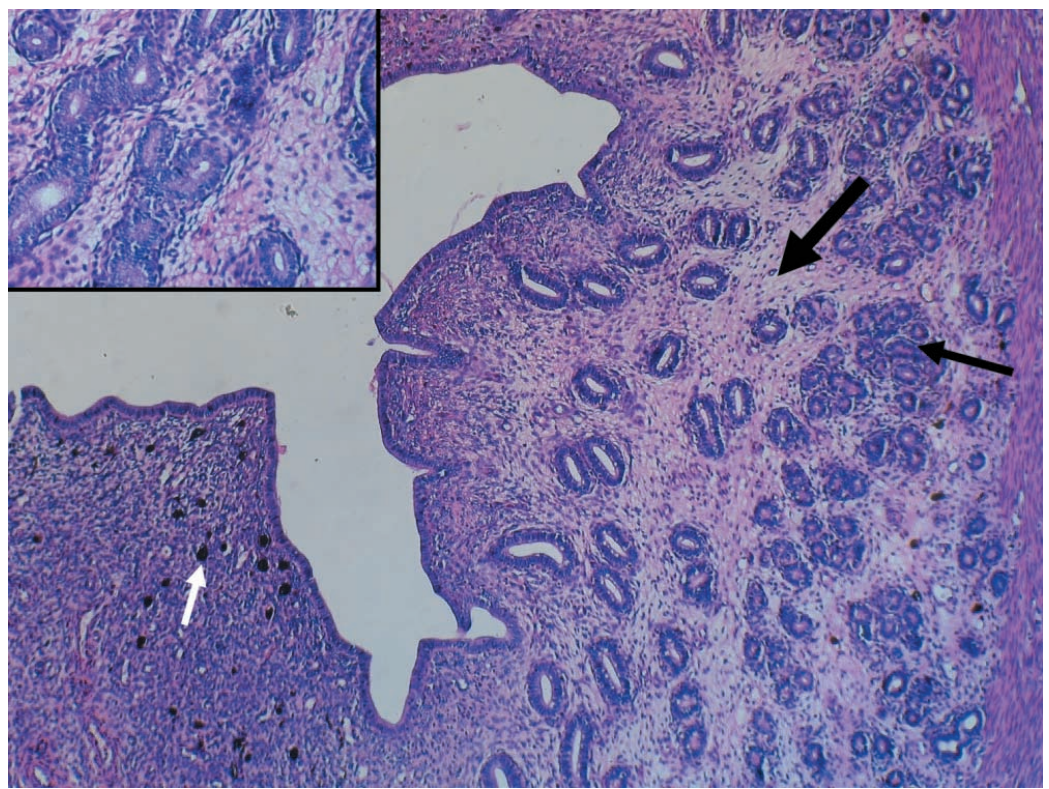

Fi. 2. Endometrio de oveja prepúber raza Araucana DPN 117. Zona intercaruncular con glándulas tubulares recubiertas por epitelio cilíndrico bajo (flecha delgada) y estroma denso (flecha gruesa). Nótese la presencia de linfocitos, neutrófilos y numerosos melanocitos en el estroma endometrial (flecha blanca). Van Gieson. 100X.

muestra áreas que sobresalen a la luz (carúnculares) y áreas que no lo hacen (intercarúnculares). Las carúnculas están determinadas genéticamente, y se convertirán en puntos de inserción placentaria durante la gestación (Priedkkalns).

Wiley et al., en sus trabajos sobre morfogénesis y citodiferenciación del útero ovino señalan que factores endocrinos actuarían durante los periodos perinatal y neonatal estimulando el desarrollo y proliferación glandular, las glándulas ausentes en el útero fetal, comenzarían a esbozarse en la región superficial con aspecto tubular algo tortuoso, tortuosidad que se acentuaría en el transcurso de los días.

La oveja es un animal poliéstrico estacional y desde que comienza su pubertad sus ciclos estrales están regulados por una secuencia rítmica intrínseca hipotálamohipófisis-ovarios que a su vez es modulada por factores ambientales y factores neuroendocrinos internos (Cunningham; Garfolo \& Tasende, 1996; Jainudeen). En el endometrio también se producen cambios cíclicos durante el estro siendo los estrógenos y la progesterona sus principales responsables. Cuando predomina la acción estrogénica las áreas carunculares se presentan como zonas aglandulares de estroma denso rico en fibroblastos con vasos prominentes. Las zonas intrecarúnculares están constituidas por endometrio funcional con glándulas en su mayor parte tubulares recubiertas por epitelio cilíndrico simple, algunas algo tortuosas, con ramificación, su estroma es compacto con vasos poco prominentes y muestra algunos linfocitos y neutrófilos aislados. Se observan células epiteliales con mucina (Jainudeen; Labadia, 1995; Priedkklans).

Posteriormente, la progesterona actúa produciendo hiperplasia con arrollamiento glandular y copiosa secreción, los vasos se hacen prominentes sufriendo luego el endometrio, si no hay fertilización, fenómenos regresivos. Hay que destacar que los cambios degenerativos y regenerativos endometriales son mucho menos notorios en las especies poliéstricas que en las monoéstricas (Priedkklans).

Durante la prepubertad se observa acción estrogénica pero esta induce pocos cambios endometriales ya que las concentraciones de estradiol ováricas son bajas en el animal inmaduro (Carpenter et al., 2003a). El endometrio presenta desarrollo moderado, no es muy grueso, encontrándose cubierto por epitelio cilíndrico, con glándulas tubulares simples algo tortuosas con ramificación inicial y estroma compacto. 


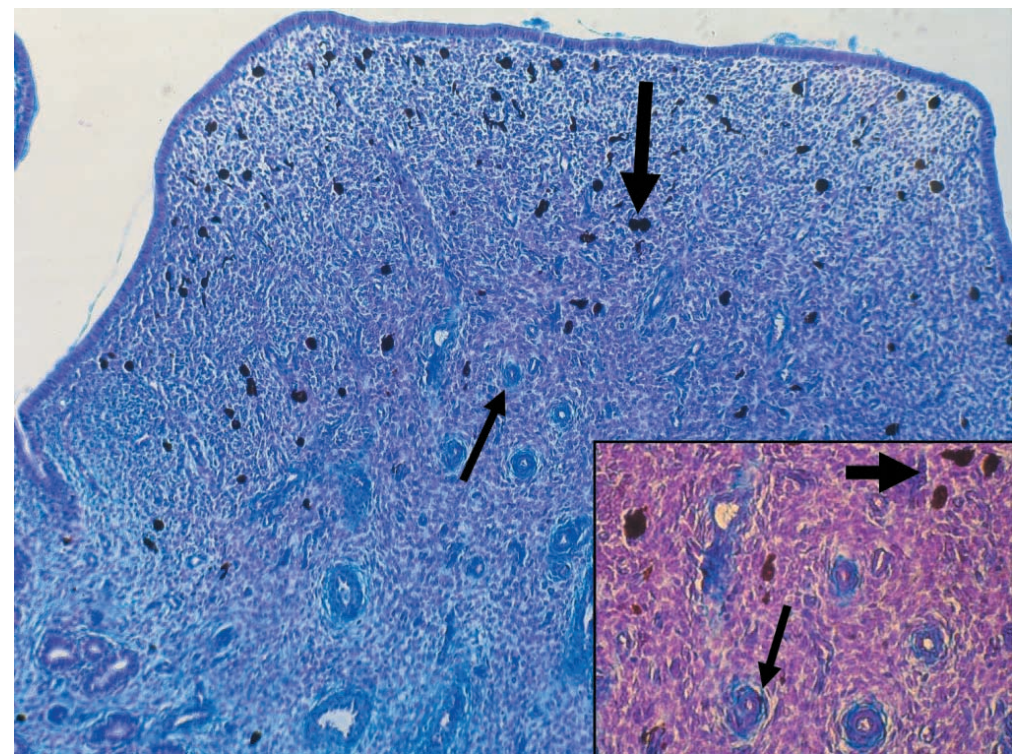

Fig. 3. Endometrio de oveja prepúber raza Araucana DPN 117. Zona caruncular, aglandular con estroma denso, bien vascularizado (flecha fina), con fibroblastos y numerosos melanocitos (flecha gruesa). Arteta 100X.

Fig. 4. Endometrio de oveja adulta unípara. Zonas intercarunculares glandulares (flecha delgada) y áreas carunculares aglandulares (flecha gruesa). HE 40X.

Fig. 5. Úteros de ovejas prepúber y plurípara. Muestran zona intercaruncular endometrial con glándulas tubulares recubiertas por epitelio cilíndrico. A zona caruncular y miometrio de oveja prepúber muestra vasos sanguíneos poco prominentes (flechas delgada y gruesa). B. zonza caruncular de oveja plurípara: abundantes vasos muy prominentes intercarunculares (flecha delgada) y miometriales (flecha gruesa). HE 100X.
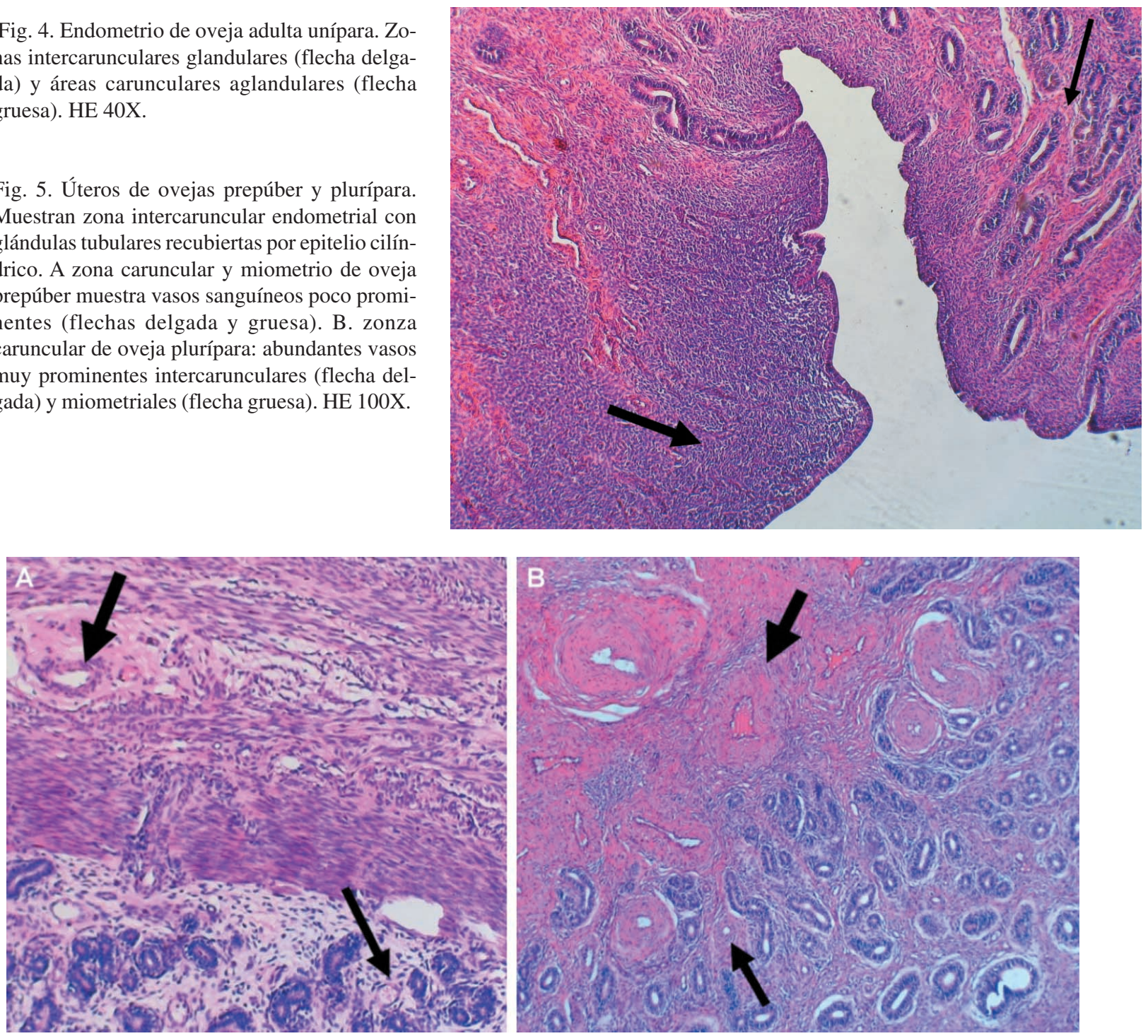
Por los resultados observados en nuestro estudio concluimos que en las ovejas prepúberes no se observan diferencias histológicas significativas entre ambas razas (Romney Marshni y Araucana) cambios morfológicos durante el transcurso de los días 93 al día 117 post natal, siendo su aspecto similar al de endometrio de la oveja adulta.
Conociendo el papel esencial que tienen los receptores esteroidales en la fisiología reproductiva al determinar el estado morfofuncional del endometrio (Cherny, 1991; Meikle, 2001; Vasconcellos et al., 2005a,b), esta investigación constituye un paso preliminar para profundizar el estudio de los receptores de estrógeno y progesterona en distintas razas de animales y con diferentes planos de nutrición.

VASCONCELLOS, C.A.; CARRASCO, R. J. \& VALDÉS, F. F. Comparative histomorphological study of prepuberal ewe endometrio of different prolificity races. Int. J. Morphol., 26(1):143-148, 2008.

SUMMARY: The aim of the present study was to sit morphological bases for the inmumocitochemical and hybridazion in situ study of the presence and distribution of estrogen and progesterone receptors in sheep of different prolificity and in different nutrition plane, centering our interest in the endometrium for its relevance in the reproductive mechanisms. We used sheep prepuberal Romney Mash of high prolificity $(n=2)$ and Araucanian of standard prolificity $(n=2)$ Immediately after slaughter uterine tissue was taken for histhological study from uteri, oviduct and ovary. Cross sections were stained with Hematoxilina-eosina, Van Giesson, Arteta and Periodic Acid of Schiff (P.A.S.). The results showed in both races a good endometrial development, with caruncular and glandular intercaruncular glandular areas well defined, the later necessary for embryo implantation and growth The numerous, tubular, coiled, glands, extend to the miometrium. No significant histological differences were observed between both races neither morphological changes between days 93 to 117 of post natal life, being their aspect similar to the endometrium of mature sheep.

KEY WORDS: Sheep; Histoendometrium; Prepuber; Prolificity.

\section{REFERENCIAS BIBLIOGRÁFICAS}

Cunningham, J. Ciclos reproductivos en Fisiología Veterinaria. Interamericana Mc Graw-Hill, México, 1998. pp. 494-502.

Cherny, R. A. Inmunohistochemical localization of estrogen receptors in the endometrium of the ewe. Reprod. Fertil. Dev. 3:32131, 1991

Carpenter, K. D.; Gray, A.; Bryan,T. M.; Welsh, T. H. \& Spencer,T. E. Estrogen and antiestrogen effects on neonatal ovine uterine development. Anat. Biol. Reprod., 69:708-11, 2003.

Carpenter, K. D; Hayashi, K. \& Spencer, T. E. Ovarian regulation of endometrial gland morphogenesis and activin-follistatin system in the neonatal ovine uterus. Biology of Reproduction, 69:851-60, 2003.

Carpenter, K. D.; Hayashi, K. \& Spencer, T. E. Neonatal estrogen exposure disrupts uterine development in the postnatal sheep. Endocrinology, 145(7):3247-57, 2004

Garfolo, E.G. \& Tasende, C. Uterine estrogen and progesterone receptors in endometrium, and caruncles. Vet. Res., 27:177-83, 1996.

Gray, C. A.; Burghardt, R. C.; Johnson, G. A.; Bazer, F. W. \& Spencer, T. E. Evidence that absence of endometrialgland secretions in uterine gland knockout ewes compromises conceptus survival and elongation. Reprod., 124:289, 2002.

Jainudeen, M. R. Ovejas y cabras. En Hafez, E. S. E. \& Hafez, B. Prepuberal ewe distribution in myometrium, B. Reproducción e inseminación artificial en animales. $7^{\mathrm{a}}$ ed. Mc Graw-Hill, México, 2002.

Kimmins, S. \& Mac Laren, L. A. Oestrous cycly and pregnancy effects on the distribution of oestrogen and progesterone receptors in bovine endometrium. Placenta 22:742-8, 2001.

Labadia, A. Bases fisiológicas de la reproducción en la hembra. En: GArcía Sacramento, A; Castejon, F.; De la Cruz, L. F.; González, J.; Murillo, M. D. \& SALIDO, G. Primer edición. Fisiología Veterinaria. Mc Graw-Hill, México, 1995. pp840-59.

Meikle, A.; Garfolo, E.G.; Tasende, C.; Rodríguez-Piñón, M. \& Shalin, L. Regulation by gonadal steroids of estrogen and progesterona receptors along the reproductive tract in female lambs. Acta Vet. Scand., 42:161-19, 2001.

Neculman, N. Manejo y productividad ovina en predios mapuches del sector Chol-Chol, IX Región de Chile. 
VASCONCELLOS, C. A.; CARRASCO, R. J. \& VALDÉS, F. F. Estudio histomorfológico comparativo del endometrio de ovejas prepúberes de razas de distinta prolificidad. Int. J. Morphol., 26(1):143-148, 2008

Thesis Ing. Agr. Universidad de la Frontera, Chile, 1991.

Priedkkalns, J. Sistema reproductor femenino. En: Dellmann, D. Histología Veterinaria. $2^{\mathrm{a}}$ ed. Acribia, Zaragoza, 1993. pp 279-83.

Sepúlveda, N.; Inostroza, K.; Bravo, S.; Rodero, E. \& Herrera, M. Comportamiento reproductivo y productivo de ovinos Romney Marsh y Araucanos en Chile. XXII Jornadas Científicas y XI Jornadas Internacionales Sociedad Española de Ovinotecnia y Caprinotecnia Mallorca. Septiembre, 2007

Vasconcellos, A.; Sepúlveda, N.; Castillo, J. \& Rosas, C. Presencia de receptores de estrógeno y de progesterona en el endometrio de ovejas prepúberes. Estudio inmunocitoquímico Int. J. Morphol., 23(4):393-6, 2005a.

Vasconcellos, A.; Peña, P. \& Sepúlveda, N. Estudio histomorfológico comparativo del endometrio de la oveja prepúber y en anestro bajo influencia hormonal cíclica. Rev. Cient. FCV-LUZ., 15(4):334-7, 2005 b.

Wiley, A. A.; Bartol, F. F. \& Barron, D. H. Histogenesis of the ovine uterus. J. Anim Sci., 64:1262-9, 1987.
Dirección para correspondencia:

Dra. Adriana Vasconcellos C.

Facultad de Medicina

Universidad de La Frontera

Casilla 54-D

Temuco, Chile

Fono: 56-45-325584

Fax: $56-45-325600$

Email: avascon@ufro.cl

Recibido: 22-11-2007

Aceptado 12:01-2008 